\title{
Double seismic zone within the ridge-shaped slab beneath southwest Japan
}

\author{
Takayuki Miyoshi ${ }^{1}$ and Kazushige Obara ${ }^{2}$ \\ ${ }^{1}$ National Research Institute for Earth Science and Disaster Prevention, 3-1 Tennodai, Tsukuba, Ibaraki 305-0006, Japan \\ ${ }^{2}$ Earthquake Research Institute, University of Tokyo, 1-1-1 Yayoi, Bunkyo-ku, Tokyo 113-0032, Japan
}

(Received June 17, 2010; Revised September 28, 2010; Accepted November 1, 2010; Online published February 3, 2011)

\begin{abstract}
We have investigated the intra-slab seismicity and focal mechanisms in the subducting Philippine Sea plate, beneath the region spanning Ise Bay and Lake Biwa, southwest Japan. Based on the hypocentral distribution of earthquakes, the slab geometry shows a gently dipping trend and ridge-shaped features, with the intra-slab seismicity forming a distinct double-plane seismic zone. The seismicity of the lower plane is much less active than that of the upper plane and is located about $10 \mathrm{~km}$ beneath the upper plane seismicity. Examination of the focal mechanism solutions revealed that the upper plane earthquakes occurred basically in a tension field, as is the case with most intra-slab events beneath southwest Japan. In contrast, we found that the lower plane earthquakes near the axis of the ridge-shaped slab occurred in a compression field. The seismogenic stress of the lower seismic plane is probably caused by the bending responsible for the formation of the ridge-shaped slab. Our analysis of earthquake waveforms confirmed that the upper and lower plane seismic zones correspond to the oceanic crust and mantle, respectively. Lateral stretching and bending of the slab could be the main driving factors that control the seismogenic stress field of the double seismic zone in this region.
\end{abstract}

Key words: Double seismic zone, intra-slab earthquakes, Philippine Sea slab, slab bending, hypocentral distribution, focal mechanisms.

\section{Introduction}

The Philippine Sea (PHS) plate is being subducted beneath southwest Japan along the Suruga and Nankai troughs (Fig. 1). Great interplate ( $M$ 8-class) earthquakes associated with the subduction of the PHS plate have repeatedly occurred along the troughs, with a recurrence interval of 100-200 years (e.g., Ishibashi, 2004). Several kinds of lowfrequency events have been recently detected at the deeper extension of the seismogenic zone, on the plate interface (e.g., Obara, 2002; Ito et al., 2007). Many intra-slab earthquakes defined by a rather inhomogeneous distribution occur within the subducting PHS plate, especially beneath the land area. The focal mechanism solutions of these earthquakes are mostly of the normal-fault or strike-slip type, with the $T$-axis in an E-W direction or trough-parallel direction, and the seismogenic stress field is basically tensional (e.g., Ukawa, 1982), while the slab geometry is complex (e.g., Miyoshi and Ishibashi, 2004). The origin of the intra-slab stress has been investigated in previous studies (Ukawa, 1982; Xu and Kono, 2002; Wang et al., 2004; Shiomi et al., 2008). Based on these results, it has been suggested that the E-W or trough-parallel tension is related to the forces acting upon the slab, for example, as slab pull, slab bending, and/or resistance against subduction.

A double-plane seismic zone (DSZ) structure for intraslab earthquakes was first identified within the Pacific plate beneath northeast Japan (Hasegawa et al., 1978). Recently,

Copyright (C) The Society of Geomagnetism and Earth, Planetary and Space Sciences (SGEPSS); The Seismological Society of Japan; The Volcanological Society of Japan; The Geodetic Society of Japan; The Japanese Society for Planetary Sciences; TERRAPUB.

doi:10.5047/eps.2010.11.001 the intra-slab seismicity within the PHS plate beneath the Kii Peninsula was also reported to have DSZ characteristics (e.g., Seno et al., 2001; Miyoshi and Ishibashi, 2004; Smith et al., 2004). Both the distribution of earthquake hypocenters in the region and arguments supporting slab dehydration suggest that the intra-slab earthquakes in the upper DSZ plane occur almost entirely within the oceanic crust, while the intra-slab events in the lower plane occur within the oceanic mantle (Seno et al., 2001; Yamasaki and Seno, 2003; Smith et al., 2004). Seno et al. (2001) also identified DSZ seismogenic layers by examining later phases associated with the slab structure. However, the seismogenic stress field of the DSZ has not been discussed to date even though its features are important for clarifying why intraslab earthquakes occur beneath southwest Japan.

Beneath the region from Ise Bay to Lake Biwa, the shallow and gently dipping slab, with a NW-SE trend, has a convex shape (Fig. 1), as inferred from the distribution of intra-slab earthquakes (Miyoshi and Ishibashi, 2004, 2008), seismic tomography (e.g., Nakajima and Hasegawa, 2007), and receiver function analyses (e.g., Shiomi et al., 2008). Miyoshi and Ishibashi (2008) called this part of the slab the Isewan-Kohoku Slab (IKS). In the study reported here, we first determined the fine hypocenter and focal mechanism distributions in and around the IKS. Based on these results, we then verified the existence of a DSZ within the subducting slab. The origin of the seismogenic stress field of the DSZ within the IKS is discussed, taking into account the geometry of the subducting slab. 


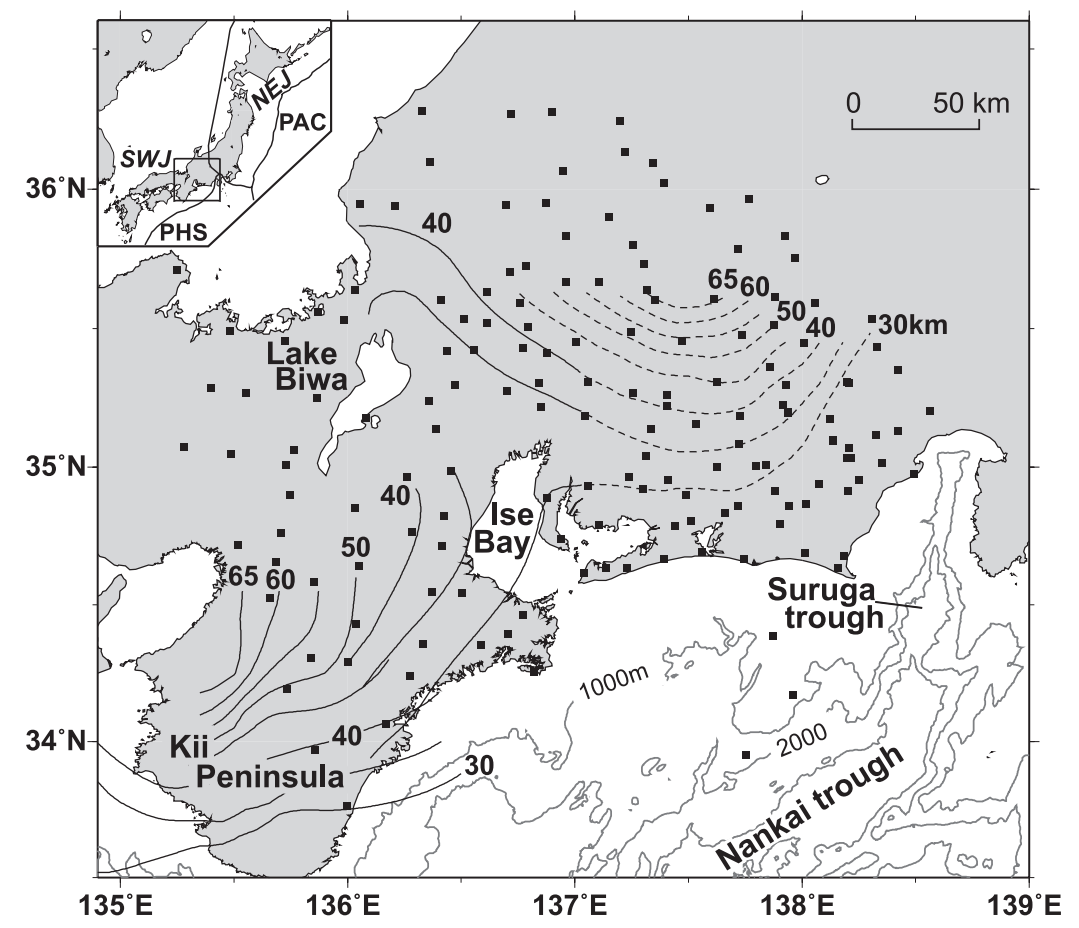

Fig. 1. Index map of the study area. Seismic stations (solid squares) used in hypocenter locations and isodepth lines of the upper surface of the Philippine Sea slab at 5-km intervals (solid and broken curves; Miyoshi and Ishibashi, 2004) are shown. Bathymetric data (in meters) are those of the Japan Oceanographic Data Center (J-EGG500). PAC, PHS, NEJ, and SWJ indicate the Pacific plate, Philippine Sea plate, northeast Japan, and southwest Japan, respectively.

\section{Data and Method}

The data used in this study were obtained by the highsensitivity seismograph network (Hi-net) (e.g., Obara et al., 2005) and the former Kanto-Tokai observation network of the National Research Institute for Earth Science and Disaster Prevention (NIED). Additional data were obtained from the Japan Meteorological Agency (JMA), Kyoto University, Nagoya University, and the University of Tokyo. About 7,000 earthquakes were selected for analysis from an earthquake catalog based on manual arrival time picking prepared by NIED Data Management Center. The analyzed earthquakes occurred between April 2002 and November 2009 beneath the region extending from Ise Bay to Lake Biwa. The focal depth of the selected earthquakes ranges from 0 to $100 \mathrm{~km}$, and the minimum magnitude threshold is 2.5 and 0.0 for events shallower and deeper than $30 \mathrm{~km}$, respectively.

The hypocenters were located with the HYPOMH program (Hirata and Matsu'ura, 1987). The $P$ - and $S$-wave arrival times of earthquakes observed at stations within an epicentral distance of $100 \mathrm{~km}$ were used for locations. Figure 1 shows the distribution of the 159 stations included in our analysis. The velocity structure (Fig. 2) is based on the "JMA2001" one-dimensional (1-D) velocity model (Ueno et al., 2002). Station corrections (between -0.5 and $0.3 \mathrm{~s}$, and $-0.8 \mathrm{~s}$ and $1.0 \mathrm{~s}$ for the $P$ - and $S$-wave, respectively) were used to minimize the effect of the unmodeled velocity structure on the location accuracy (e.g., Shibutani et al., 2005). There were 4,355 earthquakes located at depths deeper than $30 \mathrm{~km}$, with almost all of these events being intra-slab earthquakes. The depth location error for the events deeper than $30 \mathrm{~km}$ is within $2 \mathrm{~km}$, and

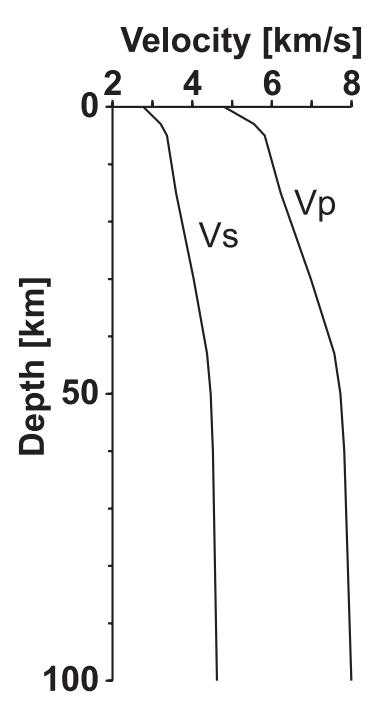

Fig. 2. $P$-and $S$-wave velocity structure used for the hypocenter locations.

the root mean square of residual travel times was reduced by using station corrections from $0.13 \mathrm{~s}$ to $0.11 \mathrm{~s}$ and from 0.28 s to 0.22 s for the $P$ - and $S$-wave, respectively.

The focal mechanism solutions for the intra-slab earthquakes were determined from initial $P$-wave motion polarities using the HASH (version 1.1) program (Hardebeck and Shearer, 2002). We analyzed only those events for which eight or more $P$-wave polarities were available. Although this technique can account for possible errors in the assumed earthquake locations and seismic velocity model, as well as in the polarity observations, we evaluated only pos- 
(a)

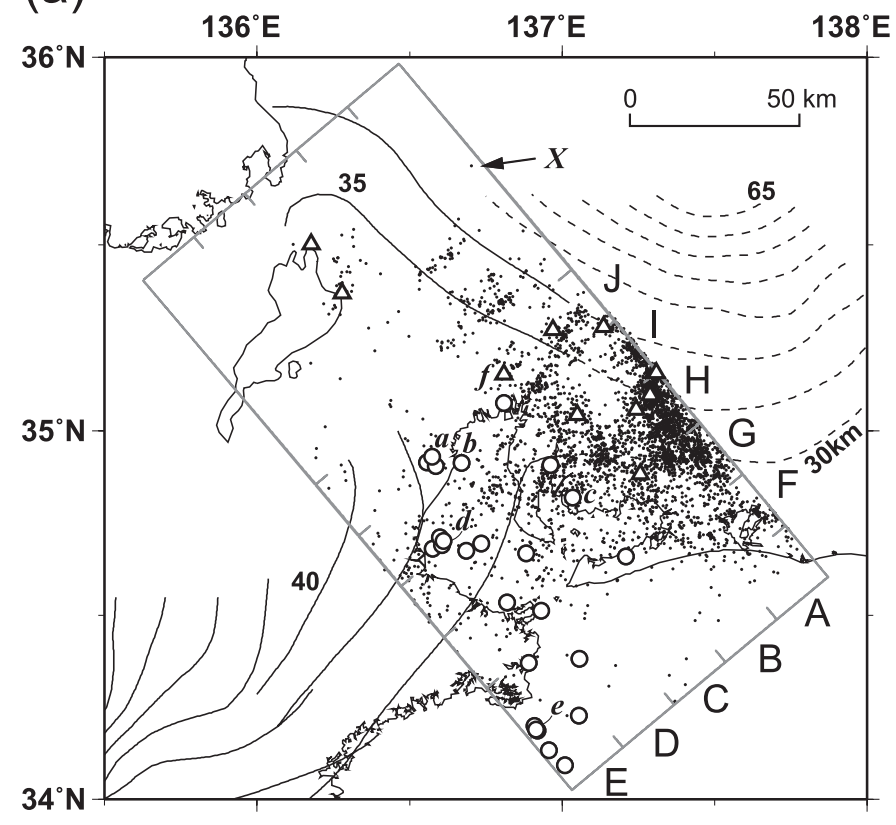

(b)
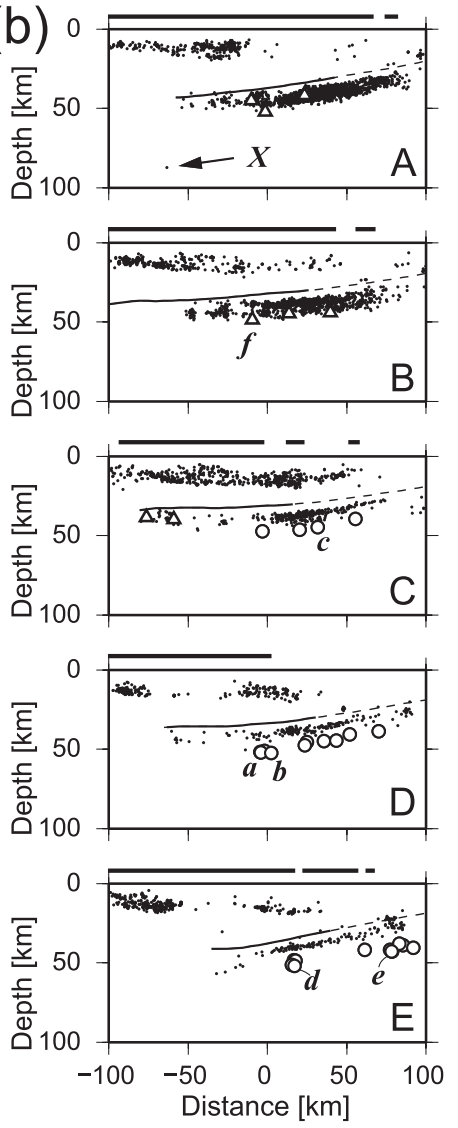
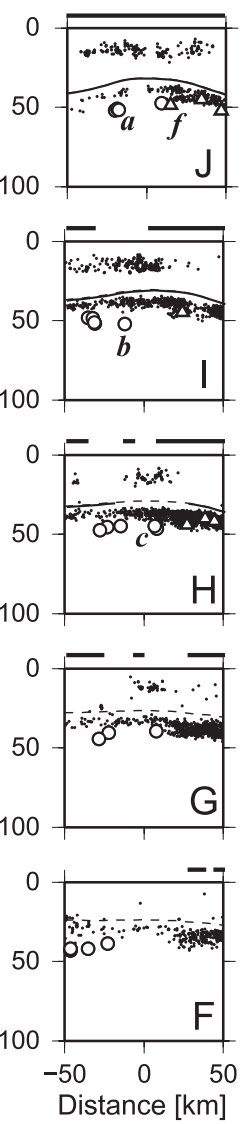

Fig. 3. Earthquake distribution obtained in this study. Dots and open circles indicate the locations of events within the upper plane and lower plane of the DSZ, respectively. Open triangles indicate the locations of reverse-fault- or strike-slip-type events with the $P$-axis orientation ranging from the E-W to the NE-SW directions. Solid and broken curves are the same as in Fig. 1. An "X" indicates the deepest event detected in this region, with the exception of the deep intra-Pacific-slab events (see discussion in Section 3). (a) Epicentral distribution of earthquakes located in this study. Earthquakes deeper than $30 \mathrm{~km}$ are shown. Symbols A to J indicate the rectangle areas used for the cross-sections in (b). (b) Vertical cross-sections of hypocenters (depth from 0 to $100 \mathrm{~km}$ ) within each rectangular area indicated in (a). Solid and broken curves show the upper surface of the PHS plate (Miyoshi and Ishibashi, 2004). Thick bars above each box indicate land areas.

sible errors associated with polarity observations. The takeoff angles and azimuths had been previously determined when the earthquakes were located. For each event, the preferred focal mechanism was taken to be the average of all acceptable solutions found by a grid search approach.

\section{Hypocenter and Focal Mechanism Distribu- tions}

The epicentral distribution of earthquakes and crosssections of hypocentral distributions obtained in this study are shown in Fig. 3. The intra-slab earthquakes can be seen to distribute at a depth of around $30-40 \mathrm{~km}$. This distribution confirms the shallow and ridge-shaped features of the slab, with an axis oriented in a NW-SE direction (Miyoshi and Ishibashi, 2004, 2008). On the northeastern side of the IKS, a small event $(M 0.8)$ occurred at a depth of about $80 \mathrm{~km}$ on August 14, 2009 (Event " $X$ " in Fig. 3). This was the deepest event in this area, with the exception of the deep intra-Pacific-slab events. If this event occurred within the PHS slab, the slab should dip at a steep angle. The possibility of a steeply dipping slab in the region was discussed by Nakajima and Hasegawa (2007), based on the results of seismic tomography.

Examination of the cross-sections of Fig. 3(b) revealed the existence of a main seismic zone of intra-slab earthquakes. A number of isolated events, located about $10 \mathrm{~km}$ below the upper plane seismicity (e.g., cross-sections C-J of Fig. 3(b)), can also be recognized. Since the hypocenters of these earthquakes were determined with sufficient accuracy, they suggest the existence of a second, lower seismic zone. We define such isolated events as lower plane earthquakes of the DSZ if they are located $7 \mathrm{~km}$ deeper than the average focal depth of the intra-slab earthquakes. In this way, we identified 25 lower plane events in the vertical cross-sections C-E of Fig. 3(b). These events are shown by open circles in Fig. 3. The largest event was M 3.0.

The $T$-axis of the earthquakes in the upper plane and the focal mechanism of some of the events in the lower plane are shown in Fig. 4. We obtained 305 well-constrained focal mechanisms (quality A and B of Hardebeck and Shearer, 2002) and also added a less-constrained focal mechanism (of quality C) for an event that occurred in the lower seismic plane. The $T$-axis of the upper plane events was almost in an E-W direction (Fig. 4). This result is consistent with previous findings (e.g., Ukawa, 1982), according to which the intra-slab events are normal-fault or strike-slip type earthquakes, with the $T$-axis oriented in an E-W direction. However, our results show that some of the analyzed events are 


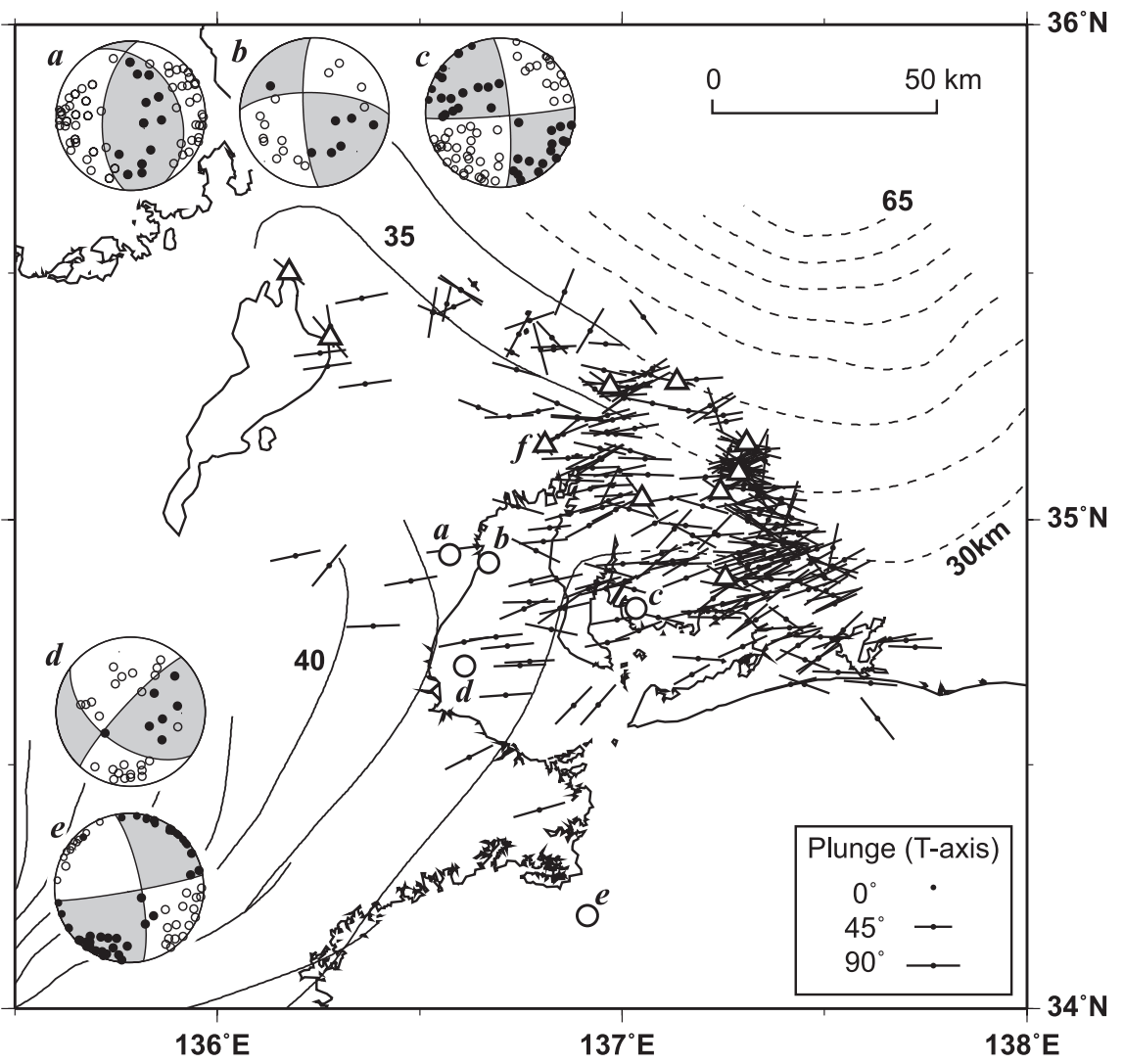

Fig. 4. Distributions of $T$-axes and focal mechanisms of the intra-slab earthquakes. Distributions of $T$-axes for the events occurred in the upper plane of the DSZ, and focal mechanisms (a-e) of the events occurred in the lower plane of the DSZ are shown. Open circles and triangles are the same as in Fig. 3. Solid and broken curves are the same as in Fig. 1.
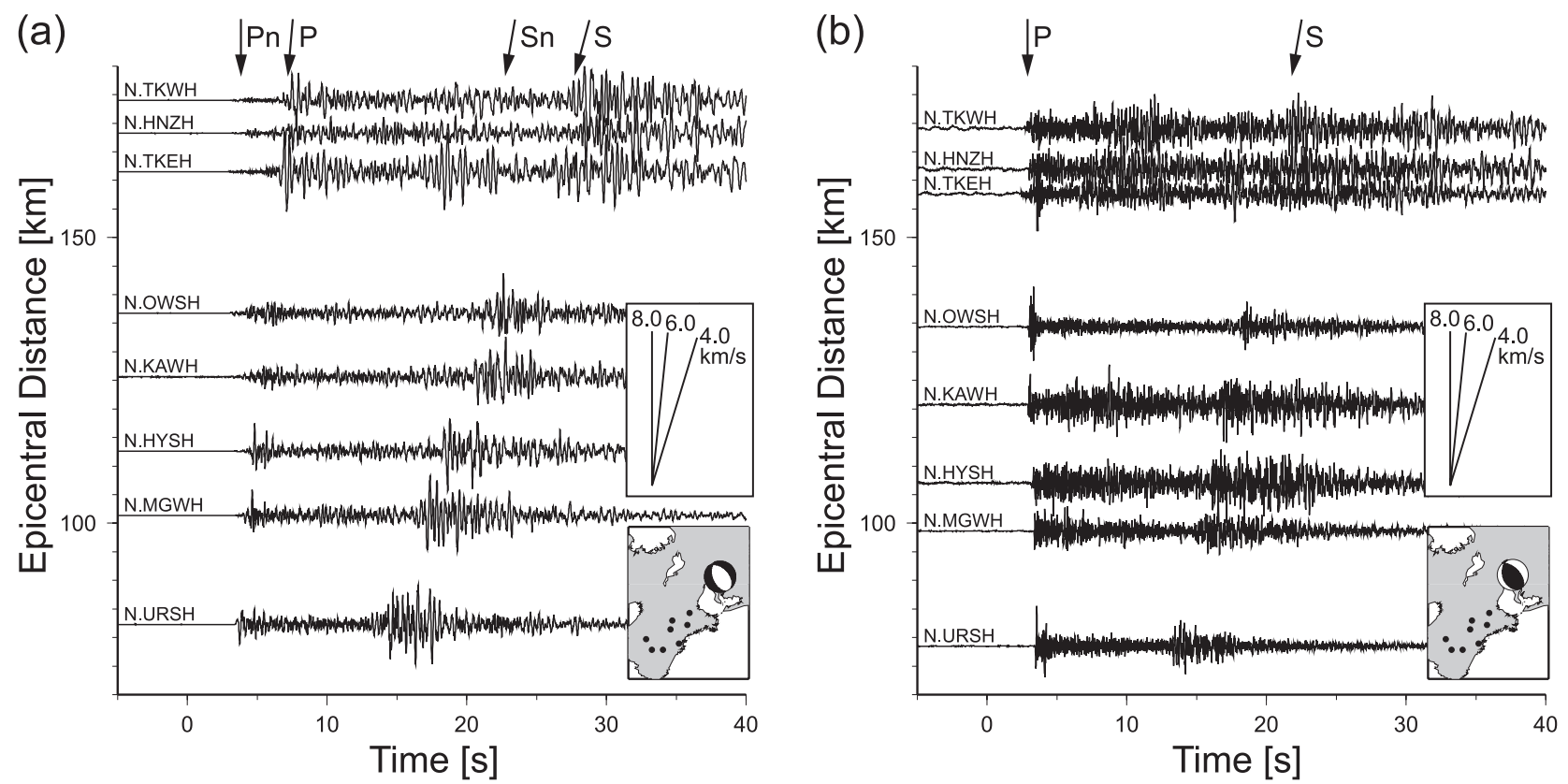

Fig. 5. Example of seismograms of intra-slab earthquakes observed at several Hi-net stations. (a) Seismograms of an $M 4.1$ event occurring at a depth of $38.3 \mathrm{~km}$ on February 7, 2003. The reduction velocity is $8.0 \mathrm{~km} / \mathrm{s}$. Arrows mark the arrivals of distinct seismic phases. $P_{n}, S_{n}, P$, and $S$ indicate oceanic $P_{n}$ wave, oceanic $S_{n}$ wave, $P$ direct wave, and $S$ direct wave, respectively. The distribution of the recording seismic stations and the focal mechanism of the event are also shown. (b) Seismograms of an M 3.0 event (event $\mathrm{f}$ in Figs. 3 and 4) occurred at a depth of $44.6 \mathrm{~km}$ on April 17, 2004. Other explanations are the same as for (a). 
of the reverse-fault or strike-slip type, with the $P$-axis orientation ranging from the E-W to NE-SW directions. Such focal mechanisms are unknown for intra-slab events within the PHS plate beneath southwest Japan. The events denoted a, b, and c, respectively, in Figs. 3 and 4, which are located in the lower seismic plane, near the axis of the ridge-shaped IKS, are characterized by such mechanisms. The main, upper seismic plane also has earthquakes of this type (open triangles in Figs. 3 and 4), with a number of these located at the bottom of the main seismic plane, near the axis of the ridge-shaped IKS (Fig. 3). These events may be classified as lower plane events (e.g., event $\mathrm{f}$ in Figs. 3 and 4). The different types of focal mechanisms in each plane indicate that two seismic zones exist within the slab.

On the other hand, two events (events d and e in Fig. 4) in the lower seismic plane are of strike-slip type, with the $T$ axis orientation in the E-W and NE-SW direction, respectively. These events were located near the southwestern end of the IKS. Such observations suggest that the stress field for the lower seismic zone is different from that of the upper zone near the axis of the IKS and is the same near the southwestern end of the IKS.

The upper and lower plane events of the DSZ occur within the oceanic crust and mantle, respectively (e.g. Seno et al., 2001; Yamasaki and Seno, 2003; Smith et al., 2004). We analyzed intra-slab earthquake seismograms to check the location (i.e., crust or mantle) of the DSZ earthquakes within the IKS. The waveforms shown in Fig. 5 are for two events with very close epicenter locations but different depths and focal mechanism solutions. For the event shown in Fig. 5(a), a pair of weak initial phases (oceanic $\left.P_{n} / S_{n}\right)$ and later phases $(P / S)$ was observed at stations along the eastern coast of the Kii Peninsula. The oceanic $P_{n} / S_{n}$ phases can be interpreted as head waves or refracted waves traveling throughout the high-velocity oceanic mantle layer. A pair of weak oceanic $P_{n} / S_{n}$ phases and later $P / S$ phases should be observed at stations if the earthquakes occur within the oceanic crust of low seismic velocities (e.g., Fukao et al., 1983; Hori et al., 1985). However, only distinct direct waves $(P / S)$ were observed at the same stations for the event shown in Fig. 5(b) (event $\mathrm{f}$ in Figs. 3 and 4). Such observations can be explained if the earthquakes were located within the oceanic mantle, rather than the oceanic crust (Seno et al., 2001; Okamoto et al., 2008). These observations are consistent with the view that the upper and lower plane events of the DSZ occur within the oceanic crust and mantle, respectively.

\section{Discussion}

Based on the distributions of hypocenters and focal mechanisms, we defined a DSZ within the ridge-shaped slab. Here we discuss the seismogenic stress of the DSZ associated with the slab geometry. One of the main features of the IKS seismogenic stress field is its trough-parallel tension for the upper plane of the DSZ. However, troughparallel compression and tension were observed within the lower plane, near the axis and southwestern end of the IKS, respectively. These features can be explained qualitatively by considering slab stretching and ridge-shaped slab characteristics as follows. Before subduction, the PHS plate

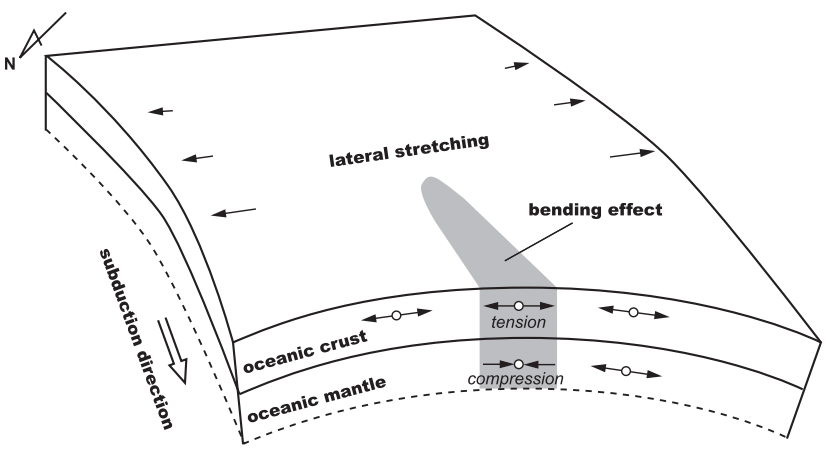

Fig. 6. Schematic illustration of the seismogenic stress field of the DSZ within the ridge-shaped slab. As the plate subducts, the slab stretches laterally. The bending effect (gray areas) appears only near the axis of the ridge-shaped slab.

near the Nankai trough is flat. As the PHS plate subducts, however, the slab stretches, as indicated by its geometry. In addition, the PHS plate also bends parallel to the trough near the Ise Bay region (F-J in Fig. 3). Only if the effect of slab stretching is large it is possible that both seismic planes may be characterized by a tensional stress field parallel to the trough, as in the southwestern part of the IKS. However, if the bending stress is larger than the effect of stretching, the compression stress field appears, as found for the lower plane near the axis of the IKS. The existence of both tension and compression fields for the DSZ within the IKS can be explained by the tension and compression stresses due to the downward bending of the IKS. Wang et al. (2004) suggested that the entire plate will become tensile under a sufficiently large stretch and, therefore, it will not generate compression stress in the bending slab. We propose that our result is a more extreme case of their findings because the strong bending overcomes locally the effect of stretching. In Fig. 6, we show a schematic illustration of the DSZ seismogenic stress field in this region. The correlation between the seismogenic stress field of the DSZ and the slab geometry should be investigated in more detail in order to gain a better understanding of the processes responsible for the occurrence of intra-slab earthquakes.

\section{Conclusions}

In this study, we located the hypocenters and determined the focal mechanisms for events that occurred beneath the region spanning Ise Bay to Lake Biwa. Our results reveal that the intra-slab seismicity within the PHS plate defined a distinct DSZ. The upper plane earthquakes were identified as being normal-fault or strike-slip types, with the $T$-axis orientation ranging from the E-W to NE-SW directions. The lower plane events could be classified into two main types: (1) thrust- or strike-slip-type events that occurred beneath the axis part of the IKS, with the $P$-axis oriented in directions ranging from E-W to NE-SW; (2) strike-sliptype earthquakes that occurred in the southwestern part of the IKS, with the $T$-axis orientation in the E-W and NE-SW direction. A study of intra-slab seismograms revealed that the events in the upper plane occurred within the oceanic crust and those in the lower plane within the mantle. These results strongly suggest the existence of a DSZ within the 
IKS. The seismogenic stress of the DSZ could be explained qualitatively by slab stretching and bending, both parallel to the trough axis.

Acknowledgments. We are grateful to NIED, Kyoto University, University of Tokyo, Nagoya University, and JMA for providing the seismic records used in this study. Eartquake magnitudes were provided by the JMA. We thank Drs. Tetsuzo Seno and Kelin Wang for valuable comments that improved our manuscript. We also thank Dr. Bogdan Enescu and researchers of the Hi-net group for their helpful comments and discussions. The GMT software (Wessel and Smith, 1998) was used to draw the figures.

\section{References}

Fukao, Y., S. Hori, and M. Ukawa, A seismological constraint on the depth of basalt-eclogite transition in a subducting oceanic crust, Nature, 303, 413-415, 1983.

Hardebeck, J. L. and P. M. Shearer, A new method for determining firstmotion focal mechanisms, Bull. Seismol. Soc. Am., 92, 2264-2276, 2002.

Hasegawa, A., N. Umino, and A. Takagi, Double-planed structure of the deep seismic zone in the northeastern Japan arc, Tectonophysics, 47, 43-58, 1978.

Hirata, N. and M. Matsu'ura, Maximum-likelihood estimation of hypocenter with origin time eliminated using nonlinear inversion technique, Phys. Earth Planet. Inter., 47, 50-61, 1987.

Hori, S., H. Inoue, Y. Fukao, and M. Ukawa, Seismic detection of the untransformed 'basaltic' oceanic crust subducting into the mantle, Geophys. J. R. Astron. Soc., 83, 169-197, 1985.

Ishibashi, K., Status of historical seismology in Japan, Ann. Geophys., 47, 339-368, 2004.

Ito, Y., K. Obara, K. Shiomi, S. Sekine, and H. Hirose, Slow earthquakes coincident with episodic tremors and slow slip events, Science, 315, 503-506, 2007.

Miyoshi, T. and K. Ishibashi, Geometry of the seismic Philippine Sea slab beneath the region from Ise Bay to western Shikoku, southwest Japan, Zisin, 57, 139-152, 2004 (in Japanese with English abstract).

Miyoshi, T. and K. Ishibashi, Neotectonics in and around the Kinki Triangle in relation to the geometry of the subducted Philippine Sea plate, Ouat. Res., 47, 223-232, 2008 (in Japanese with English abstract).

Nakajima, J. and A. Hasegawa, Subduction of the Philippine Sea plate beneath southwestern Japan: slab geometry and its relationship to arc magmatism, J. Geophys. Res., 112, B08306, doi:10.1029/2006JB004770, 2007.

Obara, K., Nonvolcanic deep tremor associated with subduction in southwest Japan, Science, 296, 1679-1681, 2002.
Obara, K., K. Kasahara, S. Hori, and Y. Okada, A densely distributed highsensitivity seismograph network in Japan: Hi-net by National Research Institute for Earth Science and Disaster Prevention, Rev. Sci. Instrum., 76, 021301, doi:10.1063/1.1854197, 2005.

Okamoto, K., T. Ohkura, and T. Seno, Seismicity within the Philippine Sea slab in the central and southern Kyushu, Japan, Zisin, 61, 77-90, 2008 (in Japanese with English abstract).

Seno, T., D. Zhao, Y. Kobayashi, and M. Nakamura, Dehydration of serpentinized slab mantle: seismic evidence from southwest Japan, Earth Planets Space, 53, 861-871, 2001.

Shibutani, T., Y. Iio, S. Matsumoto, H. Katao, T. Matsushima, S. Ohmi, F. Takeuchi, K. Uehira, K. Nishigami, B. Enescu, I. Hirose, Y. Kano, Y. Kohno, M. Korenaga, Y. Mamada, M. Miyazawa, K. Tatsumi, T. Ueno, H. Wada, and Y. Yukutake, Aftershock distribution of the 2004 Mid Niigata Prefecture earthquake derived from a combined analysis of temporary online observations and permanent observations, Earth Planets Space, 57, 545-549, 2005.

Shiomi, K., M. Matsubara, Y. Ito, and K. Obara, Simple relationship between seismic activity along Philippine Sea slab and geometry of oceanic Moho beneath southwest Japan, Geophys. J. Int., 173, 10181029, doi:10.1111/j.1365-246X.2008.03786.x, 2008.

Smith, A. J., P. R. Cummins, T. Baba, S. Kodaira, Y. Kaneda, and H. Yamaguchi, Intra-plate seismicity in the subducting Philippine Sea plate, southwest Japan: magnitude-depth correlations, Phys. Earth Planet. Inter., 145, 179-202, 2004.

Ueno, H., S. Hatekeyama, T. Aketagawa, J. Funasaki, and N. Hamada, Improvement of hypocenter determination procedures in the Japan Meteorological Agency, Q.J. Seismol., 65, 123-134, 2002 (in Japanese with English abstract).

Ukawa, M., Lateral stretching of the Philippine Sea plate subducting along the Nankai-Suruga trough, Tectonics, 1, 543-571, 1982.

Wang, K., I. Wada, and Y. Ishikawa, Stresses in the subducting slab beneath southwest Japan and relation with plate geometry, tectonic forces, slab dehydration, and damaging earthquakes, J. Geophy. Res., 109, doi:10.1029/2003JB002888, 2004

Wessel, P. and W. H. F. Smith, New, improved version of the Generic Mapping Tools released, Eos Trans. AGU, 79, 579, 1998.

$\mathrm{Xu}$, J. and Y. Kono, Geometry of slab, intraslab stress field and its tectonic implication in the Nankai trough, Japan, Earth Planets Space, 54, 733742, 2002.

Yamasaki, T. and T. Seno, Double seismic zone and dehydration embrittlement of the subducting slab, J. Geophys. Res., 108, doi:10 1029/2002JB001918, 2003

T. Miyoshi (e-mail: miyoshi@bosai.go.jp) and K. Obara 